\title{
项目教学法在电子信息工程教学中的应用实践
}

\section{The Application of PBL in Electronic Information Engineering Teaching}

\author{
赵亚飞 \\ Yafei Zhao \\ 甘肃钢铁职业技术学院 中国·甘肃 嘉峪关 735100 \\ Gansu Iron and Steel Vocational and Technical College, Jiayuguan, Gansu, 735100, China
}

\begin{abstract}
摘 要: 目前, 很多先进技术已融入各个时期的教学中, 教学创新改革已成为必然趋势, 促使教学重点、教学难点不断变 化。教师必须注重教学方式的转变及优化, 引进项目教学法, 将教学重点放在学生实践能力、操作能力培养方面, 实现教 学的预期目标, 论文主要针对项目教学法在电子信息工程教学中的应用实践进行了分析。
\end{abstract}

\begin{abstract}
At present, many advanced technologies have been integrated into the teaching in various periods, and teaching innovation and reform has become an inevitable trend, which promotes the constant change of teaching key points and teaching difficulties. Teachers must pay attention to the change and optimization of teaching methods, introduce PBL, focus on the cultivation of students' practical ability and operational ability, and achieve the expected goal of teaching. This paper mainly analyzes the application of PBL in electronic information engineering teaching.
\end{abstract}

关键词: 项目教学法; 电子信息工程教学; 应用实践

Keywords : PBL; electronic information engineering teaching; application practice

DOI : $10.36012 /$ sde.v2i11.2396

\section{1 引言}

在新课程教育教学改革的新形势下, 教师逐渐认识到 项目教学法的重要性, 其主要原因是项目教学法的灵活性比 较强, 通过设置实际项目, 有利于拓展教师、学生的思维。 电子信息工程教学的实践性比较强, 教师需要合理将项目教 学法渗透到教学全过程中, 优化现有的教学流程, 实现预期 的教育教学目标。

\section{2 项目教学法的应用优势}

项目教学法应用过程的本质是学生积极参与的创造性 实践活动，重点是项目完成的整个过程中。在项目实践过程 中, 学生需要掌握教学要求、教学技能, 体验教学创新的趣 味性, 进一步提升学生的问题解决能力, 还需要组织不同专 业学生积极参与项目教学活动, 积极开展实践训练活动, 通 过学生的共同努力进行探究 ${ }^{[1]}$ 。同时, 在实际教学实践工作
中, 教师必须积极引导学生积极应用理论基础知识, 明确学 生在课堂中的关键地位, 这样学生可以结合自己掌握的理论 知识、实践项目情况，自主完成实际项目，促使学生在教师 正确引导下, 为教学活动的高效进行提供支持。除此之外, 教师通过实施这一教学模式, 在一定程度上扩展了视野, 有 利于提高自身的专业技能、综合水平。因此，项目教学法需 要教师、学生的协调、配合, 通过实行双向发展共赢模式, 实现教学的预期目标。

\section{3 项目教学法在电子信息工程教学中的重要性}

在电子信息工程教学实践过程中，引进更多现代化教 学模式, 引导学生将教材内容、实践进行融合。在新课改背 景下，电子信息工程是高科技信息时代的关键，其教学内容、 实践应用范围都发生了很大变化, 为了适应信息时代的发 展，教师在开展电子信息工程教学活动时，必须引进项目教

【作者简介】赵亚飞(1984），女，宁夏灵武人，中级职称，从事电子信息工程研究。 
学法, 引导学生在项目实验过程中独自完成实践操作, 将学 生培养成国家发展的中坚力量。

\section{4 项目教学法在电子信息工程教学中的应用 现状}

\section{1 综合型实验教学有待完善}

电子信息工程具有计算机、通信等多学科特性, 并对 理论实践提出了更高的要求，还具有融合性、渗透性等特点， 将其和其他学科进行融合，会形成完善的结构体系，在解决 复杂试验项目问题中具有重要作用 ${ }^{[2]}$ 。但是，教师只注重学 生的学习成绩, 将教学重点放在理论课程方面, 理论教学资 源明显多于实践环节，导致综合性实验开出率相对较低，出 现了“重理论、轻实践”的问题。

\section{2 教学实验方式与途径不适用}

统一安排教学任务、规划教学流程, 学生只需根据教 师的实际要求进行, 完成教师布置的实验任务, 获取准确的 实验结果, 这样就能够完成教学活动的各项任务。在教学实 验过程中，学生往往会完全按照教师规划任务、流程完成实 际工作，未深入分析实验的原理，导致学生无法全面了解教 学内容。另外, 学生对实验原理的认知存在一定的偏差, 很 难从根本上理解、掌握理论和实践相关的知识技能, 无法满 足新时期的教学要求。

\section{5 项目教学法在电子信息工程教学中的应用 实践策略}

\section{1 根据教学需求选择合适的项目}

电子信息工程学科的专业性比较强, 这一学科的教学 重点是引导学生掌握基础理论知识, 将所学知识积极应用到 实践中。但是，电子信息工程课程内容相对较多，具有一定 的复杂性，导致学生无法在短时间内完全吸收、掌握所学知 识，很难将这些内容应用到实践操作中。为了有效解决这一 问题，教师需要根据班级实际情况，合理设置、选择教学内 容，引导学生将电子信息工程技术相关知识应用到实践中。 例如，某高校电子信息工程技术教师，根据教学内容设计具 有一定难度的实践项目，学生可以根据自己的实际情况、兴 趣特点进行自主选择，通过一学期教学实践提高了教学的整 体效果，并得到了广大师生的青睐。

\section{2 灵活展开电子信息工程教学项目}

在开展电子信息工程教学活动的过程中, 教师和学生 需要密切配合, 明确需要探究的教学项目, 随后教师、学生 选择多元化方式合理设置项目，并开展灵活的探究活动。在 全面落实电子信息工程教学准备阶段，教师需要拟定完善的 项目规划，并实施项目教学方法，在遇到某一问题时，教师 需要进行自主分析，实行合理的方案，有效解决教学难题。 例如，在“模拟电路”教学过程中，教师应实行分组探析的 项目教学法 , 在实施过程中，教师应为学生预留更多的课余 时间，搜索电路模拟相关的实例，随后带到教室和同学进行 分享，这样学生能够了解电子信息技术工程的基本原理、思 路，在遇到相关难题的情况下，教师只需进行引导，学生就 能够明确后期探究方向。

\section{3 全面检查评估教学效果}

在完成教学项目任务后，教师需要认真阐述项目原理、 优势、不足，在这一过程中总结更多的实践经验，提交项目 任务总结报告 ${ }^{[3]}$ 。另外，教师在教学实践过程中，教师需要 实行学生自主评价、相互评价融合的方式，针对学生项目任 务记录、成果效果、成果报告、学习态度等内容进行考核， 提高教学的整体效果。

\section{6 结语}

综上所述, 在电子信息工程教学过程中, 教师需要积 极引进项目教学法, 这种教学方法属于创新型教学方法中的 典型代表，改善了传统教学方法的局限性，在一定程度上激 发了学生的学习积极性，引导学生自主解决实践问题，有效 提升学生的自主学习能力, 更好地发现并解决实践问题。除 此之外，在项目教学实践过程中，学生通过参与实际项目， 可以更好地理解教材内容及要求，提高学生的问题分析、问 题解决等综合能力。

\section{参考文献}

[1] 刘萌. 项目教学法在 " 数字电路 " 课程教学中的实践应用 [J]. 现代职业教育 ,2017,4(4):240.

[2] 苏娜, 陈跃, 梅盼, 等. 结合仿真与实验的项目教学法在电力 电子技术课程中的应用 [J]. 科教导刊, 2019,367(3):133-134.

[3] 曾敬. 项目驱动教学法在电子信息类课程中的应用与实践 [J]. 信息与电脑 : 理论版 , 2018,417(23):257-258. 